South African Journal of Geomatics, Vol. 6. No. 2, Geomatics Indaba 2017 Special Edition, August 2017

\title{
Evaluating public ambulance service levels by applying a GIS based accessibility analysis approach
}

\author{
Ethel Baloyi, Hunadi Mokgalaka, Cheri Green and Gerbrand Mans \\ Built Environment, Council for Scientific and Industrial Research (CSIR) \\ P O Box 395, Pretoria, 0001, South Africa \\ Meiring Naude Road, Brummeria, South Africa \\ Tel: +27128412227 / Fax: +27128414036 \\ ebaloyi1@csir.co.za
}

DOI: http://dx.doi.org/10.4314/sajg.v6i2.3

\begin{abstract}
Ambulance vehicles are required to respond rapidly to medical emergencies. A number of factors may affect response times, most importantly the location of emergency services stations, the number of ambulance vehicles available at each station, road conditions and traffic volumes. To support spatial planning and provide input to the Integrated Development Plan of the City of Tshwane, a GIS based analysis of ambulance response time was undertaken. The purpose was to make recommendations aimed at the improved placement of stations and allocation of ambulances per station to improve service delivery through reducing the likely response times of ambulance services within the Tshwane Metropolitan area. The key input parameters used included the spatial distribution of demand (population), supply (station locations and ambulance numbers) and emergency road speeds These were tested against a provision standard of one ambulance per 30000 people. The response target applied in suburban areas was 15 minutes but 40 minutes in low density outlying areas. The results show that the current emergency services stations' locations are well distributed within the metropole; however, there seems to be a spatial mismatch in vehicle allocation. The paper discusses the impact of the two demand scenarios, namely: universal reliance on public ambulance services versus public ambulances only serving those without medical insurance. The paper concludes that GIS provide an extremely versatile and useful means of testing the implications of demand scenarios and standards relating to these factors of service provision and thereby contribute to better informed decision making.
\end{abstract}

Keywords: Ambulance vehicles, response time, emergency services, accessibility, GIS.

\section{Introduction}

The aim of this study was to test specified provision standards and make input to the efficient placement of public (municipal / provincial) ambulance stations and allocation of ambulance vehicles per station to achieve the best possible response times for ambulance services within the Tshwane metropolitan area. To do this it was necessary to audit the current supply and distribution of stations to identify areas where the supply and demand for ambulances is not balanced with the population 
demand and then to propose adjustments to achieve a service which is spatially just. The City of Tshwane wanted to test both a higher provision standard than proposed by the provincial authority, as well as the requirement to serve universal demand versus only providing the service to people who are not medically insured. The output of the analyses served as input into the municipal strategic documents (IDP and BEPP).

In the sections that follow, Section 2 provides a brief literature review of related studies and any standards applied. The methodology as applied in the study is described in Section 3 while Section 4 provides a discussion of the results of the accessibility analysis process. Recommendations for interventions are addressed in Section 5, and the paper ends with a short description of some of the limitations and challenges encountered (Section 6) and finally the conclusions reached (Section 7).

\section{Literature review}

The use of Geographic Information Systems (GIS) to locate public facilities has been used extensively in South Africa over the past 15 years allowing for the modelling of spatial accessibility using population, road network and facility location data. Green et al. (2009) describe how applied GIS-based accessibility analysis planning has been used to evaluate access and availability to public facilities based on agreed provision standards, this in turn leads to improvements in governance through focused capital investment to the areas of greatest needs. GIS-based accessibility analysis is considered a logical method which can be applied to test the degree to which equitable access to services and facilities is obtained (Mokgalaka et al., 2014). Guargliardo et al. made use of GIS in their study on the spatial accessibility of primary care and make use of what they describe as the technologically advanced concept of distance and supply to undertake "spatial accessibility"; a timely development, as the geographic information systems necessary to exploit these newer methods become more powerful, commonplace and easier to use (Guargliardo et al., 2004).

Studies that relate to EMS response time and the location of EMS stations date more than 40 years back. Studies by others predict the amount of resources required to obtain a certain (average) response time. For example, they predict the number of rescue units required, but not where to place these units (Kolesar et al., 1973). Since then there has been a growing body of work where use is made of geographic accessibility for rescue services where the location of units can be considered. One of the main components in evaluating ambulance service levels requires determining ambulance response time to specified locations. Geertman et al. used the accessibility analysis approach in their study of ambulance response (Geertman et al., 2004). Some authors adopted GIS technology and methodology that used digital road network data within a GIS system to model the transportation times from patient locations to hospitals over large geographic areas (Patel et al., 2012). In the absence of actual trip data it is noted that geographic access studies often focus on using the GIS modelled travel time from the incident scene (origin) to arrival at the hospital (destination) to test the efficiency of service locations. 
A number of studies evaluating ambulance public service levels have used different methods. Stein in his model of ambulance response in Cape Town, South Africa, applied the technique of a simulation model (Stein et al., 2015). He tested the travel time of the primary response vehicles and ambulances. The study concluded that the addition of emergency vehicles to an urban EMS system improves response times in Priority 1 incidents. He did however qualify this by indicating that the numerically sufficient number of vehicles alone is not the only improvement needed to meet or improve the national response time targets. No specific research was found on the use of GIS-based accessibility analysis to evaluate ambulance station location in South Africa although it has been used by CSIR to evaluate other Emergency Medical Services such as fire stations. In a more recent study (Green et al., 2014) applied GIS-based accessibility analysis to determine the location of additional fire stations in the eThekwini metropolitan municipality in South Africa. Since fire stations and ambulance station locations both use the emergency response road network and have similar location requirements this study provides a useful approach to evaluating other emergency service locations.

\section{Methodology}

As seen from the literature review, GIS based accessibility analysis is a useful tool for analysing gaps in public facility provision, testing the impact of different provision standards, as well as testing the location and capacity of the stations in relation to the location of identified users groups. The study was undertaken using the step-wise facility location planning approach as developed by CSIR over a number of years (Naudé et al., 2001 and Green et al., 2009). The first step involved the determination of standards with regards to capacity and travel time and concludes with the development of the intervention strategy based on the results of the GIS processes applied.

\subsection{Accessibility analysis processes}

Detail level accessibility analysis requires three key data sets, namely: the demand in this case based on the population or part thereof; the road network with accurate road speed attributes to closely reflect actual travel use; and, the facility location and capacity data. Table 1 shows the main GIS analysis process used for the ambulance accessibility evaluation. 
South African Journal of Geomatics, Vol. 6. No. 2, Geomatics Indaba 2017 Special Edition, August 2017

Table 1. Main GIS tasks and processes used for accessibility analysis of ambulances

\begin{tabular}{|c|c|c|}
\hline Task & Process undertaken & Data Source \\
\hline \multirow[t]{2}{*}{$\begin{array}{c}\text { Task } 1 \\
\text { Data Preparation }\end{array}$} & $\begin{array}{l}\text { Divide the City of Tshwane into } \\
\text { analysis unit (30ha hexagons) } \\
\text { Demand profiling: allocate population to } \\
\text { the analysis unit-universal and } \\
\text { uninsured population }\end{array}$ & $\begin{array}{l}\text { Population (Census 2011) } \\
\text { and adapted based on } \\
\text { Medical insurance data } \\
\text { (StatsSA) }\end{array}$ \\
\hline & $\begin{array}{l}\text { - } \quad \begin{array}{l}\text { Road network preparation and } \\
\text { customising for emergency road speed }\end{array} \\
\text { - Location and capacity data }\end{array}$ & $\begin{array}{l}\text { Road network adapted } \\
\text { from AfriGIS ( City of } \\
\text { Tshwane input) } \\
\text { City of Tshwane }\end{array}$ \\
\hline $\begin{array}{c}\text { Task } 2 \\
\text { Analysis }\end{array}$ & $\begin{array}{l}\text { - } \\
\text { - } \\
\text { Sufficiency analysis: capacity and } \\
\text { distance for the two population scenarios }\end{array}$ & \\
\hline $\begin{array}{l}\text { Task } 3 \\
\text { Mapping }\end{array}$ & $\begin{array}{ll} & \text { Travel time maps } \\
\text { - } & \text { Density of well served areas maps } \\
\text { - } & \text { Density of poorly served areas maps }\end{array}$ & \\
\hline
\end{tabular}

\subsection{Input standards}

An essential component of the project was to establish the travel time standard against which to test the response time as well as a vehicle provision ratio per population (capacity). The response time targets proposed for Gauteng is 15 minutes ambulance response time in urban areas, and 40 minutes in rural areas. Through stakeholder interaction it was agreed to use these standards for the analysis. In discussion with the City of Tshwane Emergency Services Department officials it was agreed to test a standard of 1:30 000 population for the purpose of strategic planning and budgeting, although this standard is more stringent than the 1:45 00 population indicated for the province.

\subsection{Data preparation}

To achieve suitable fine grained analysis required for detailed spatial planning the City of Tshwane was tessellated into small analysis units of 30 hectare hexagons.

\subsubsection{Demand profile layers - Population}

The 2011 census population formed the base data for the analysis from which the two demand profiles were identified and the total population was updated based on the 2014 mid-year estimate (StatsSA). The population of 3125607 people was disaggregated to hexagons) by the CSIR using dasymetric mapping principles (Mans, 2012). See Figure 1. The second demand profile was developed to represent the medically uninsured population (people without medical aid). The uninsured population makes up 2373948 people (71.9\% of the 2014 population) as provided by Statistics South Africa (Mokgalaka et al., 2014). The lower population demand when looking at the uninsured population layer can be noted in the suburban core areas when comparing the two maps (Figure 1).The ambulance vehicle sufficiency was tested against both two population demand profiles to better inform planning. 


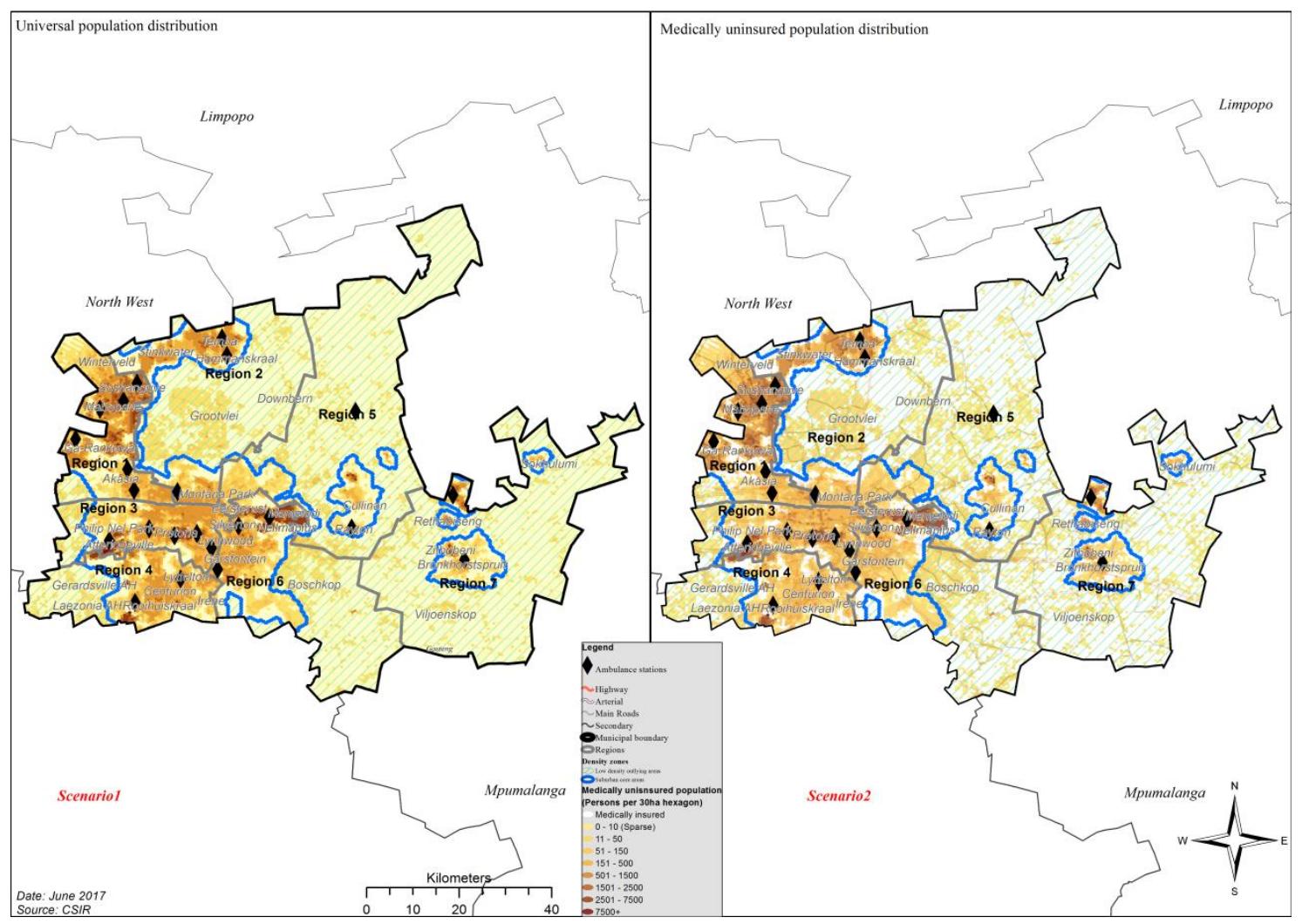

Figure 1: Population distribution

\subsubsection{Supply / Capacity layer-Location of ambulance stations)}

The location of current emergency service stations (ambulance stations) as obtained from the City is shown in relation to both demand maps. In 2014 the City of Tshwane had a total ambulance vehicle fleet of 66 vehicles which at a city level meets the requirements in terms of the Gauteng Department of Health Provincial provision norms of one ambulance per 45000 people. Nine vehicles are reserved for special events (e.g. sport tournament) and cannot be available at all times and were thus excluded from the supply capacity. Thus 57 ambulance vehicles distributed across the stations served as the main capacity constraint at a provision ratio of 1: 30 000. Without undertaking a GIS assessment this means the vehicles available can only meet $55 \%$ of the universal demand although it is very close to the Gauteng standards of 1: 45000 .

\subsubsection{Density zones}

To test the two different response time standards for urban and rural areas, two settlement types had to be demarcated. This was done based on population density and continuity of development pattern. These density zones also formed the basis for reporting the accessibility and sufficiency results. The two settlement types demarcated are as follows:

- Suburban core: Comprises most of the built up areas of the city covering the concentrations of high rise buildings, the inner City of Tshwane, and high density residential areas. These areas have an average density of 14 persons per hectare. 
- Low density outlying / rural area: Comprises peripheral areas and large intervening areas where the population density is less than 0.2 persons per hectare. These areas are mostly farms or undeveloped areas.

\subsubsection{Road Network and calibration of emergency road speeds}

A road network is an important attribute layer for measuring the actual time travelled by ambulance vehicles to all areas in the City. The road network layer obtained had length attributes but it was required to be customised and partially calibrated for the emergency speed per link with input from city officials (Figure 2). This network is used in the analysis to link all origins (hexagon centroids) in the city to the nearest ambulance station using shortest path analysis.

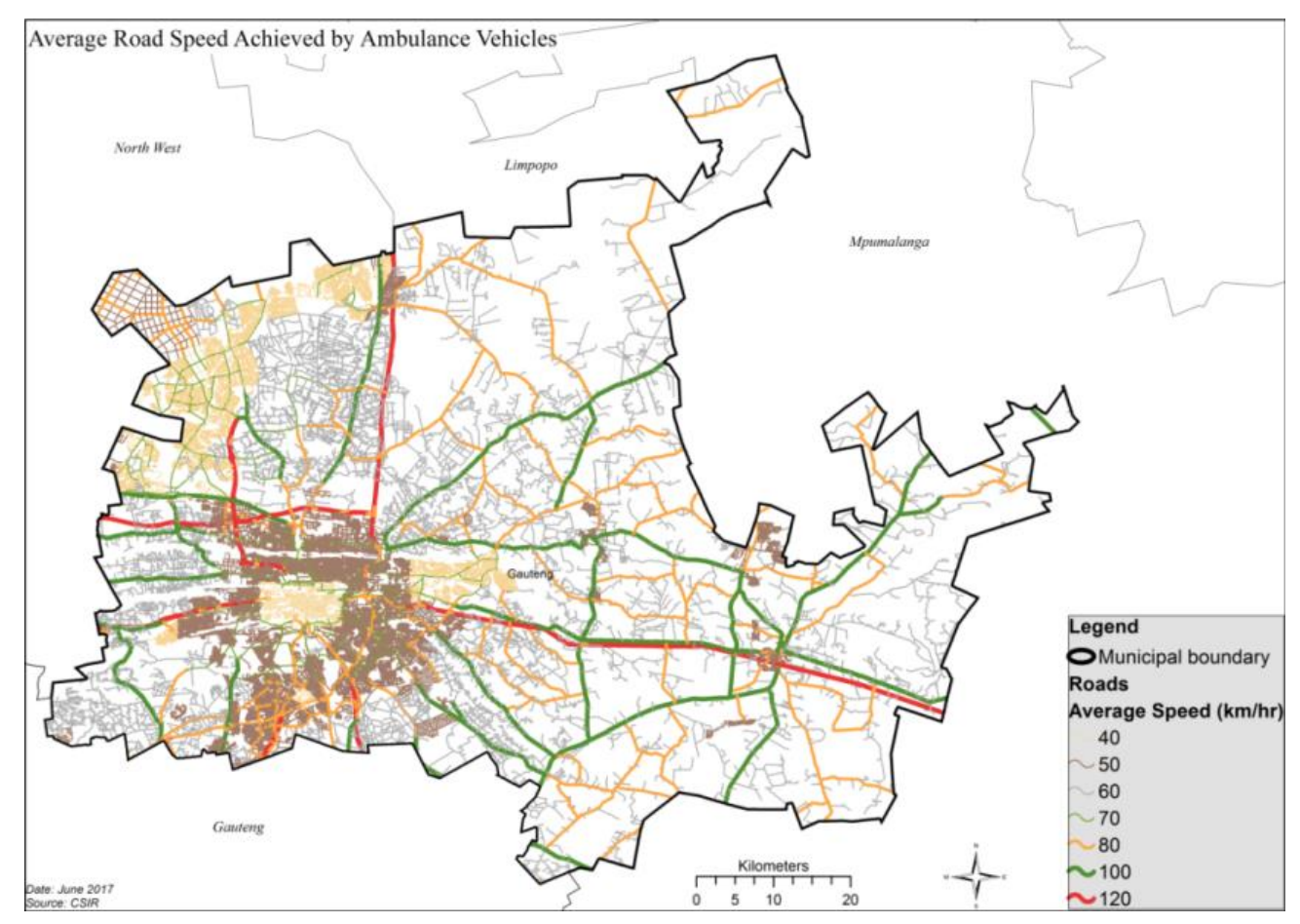

Figure 2: Average road speed achieved by ambulance vehicles

\subsection{Analysis processes applied}

The first step in the analysis process was to test response time from stations. This was done using a travel time analysis but not including ambulance capacity (number of ambulance vehicles). To test

sufficiency, a doubly constrained capacity and distance analysis was tested against both demand layers.

Table 2 shows a summary of the analysis criteria applied in the study. 
Table 2. Analysis criteria

\begin{tabular}{|c|c|c|c|}
\hline $\begin{array}{l}\text { Facilities } \\
\text { analysed }\end{array}$ & $\begin{array}{l}\text { Travel network response } \\
\text { time (standards) }\end{array}$ & Demand & $\begin{array}{l}\text { Supply } \\
\text { (Threshold } \\
\text { capacity) }\end{array}$ \\
\hline $\begin{array}{l}23 \text { Ambulance } \\
\text { stations }\end{array}$ & $\begin{array}{l}15 \text { minute response } \\
\text { time in suburban core } \\
\text { areas. }\end{array}$ & $\begin{array}{l}\text { 1. The City of Tshwane } 2014 \\
\text { total population } \\
=3125607 \text { people }\end{array}$ & $\begin{array}{c}23 \text { Ambulance } \\
\text { stations with a } \\
\text { total of } 57 \\
\text { ambulances @ } \\
\text { 1:30000 people }\end{array}$ \\
\hline
\end{tabular}

\section{Results}

\subsection{Response time analysis}

The response time only analysis results (which excludes ambulance capacity) show that the location of stations and the area coverage with respect to achieving the required response times from all ambulance stations to all areas in the City is excellent. In the suburban core areas, $99.7 \%$ of the population are within reach within the required response time of 15 minutes. In the low density outlying areas almost $100 \%$ of the population are within reach within the required 40 minute response time; although some areas are out of reach (Figure 3). These results do not consider vehicle numbers or capacity. The average response time is only 3.1 minutes travel time in suburban areas and 7.5 minutes in low density outlying areas. This confirms that the main issue that needs to be considered is the vehicle allocation per station and the population provision ratio.

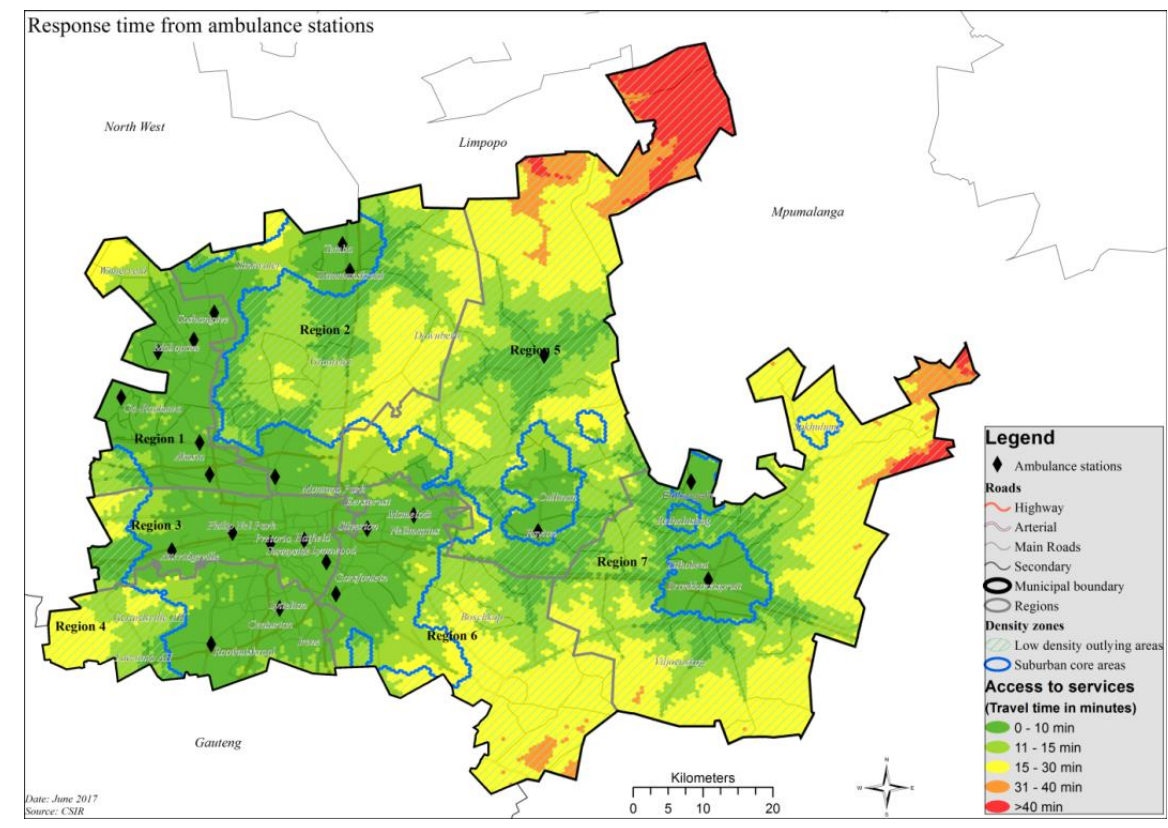

Figure 3: Response time coverage from the closest ambulance station

\subsection{Comparative analysis between the two population demand layers}


To test the sufficiency and spatial distribution of ambulance vehicle allocation per station a combined doubly constrained capacity (number of ambulance vehicles) and distance analysis was done. The analysis used the 2014 population distribution for both the universal population demand as well as demand from only those people that are not insured medically. This enabled a comparison of the allocated vehicles required per station for both planning scenarios and enabled the exploration of the implication for each demand scenario in terms of vehicle requirement and allocation. The results of the both analyses show a poor match between the supply vehicles in relation to the population distribution. Figure 4: Map 1 shows those areas that are serviced based on the vehicle to population ratio within the required response time for the universal demand scenario. The very small service regions around most stations show that they do not reach the $15 \mathrm{~km}$ distance band; it can be presumed that most ambulance stations run out of capacity and that the supply of ambulances is potentially fully allocated before all the population within reach can be allocated to the station. This confirms that the number of ambulance vehicles is inadequate in most areas based on the significant shrinkage areas per station service catchment area in comparison with the travel time only results (Figure 3).

To identify the areas most in need of service, the distribution and density of the population not served within the required response standards was mapped and is shown in Figure 4: Map 3. The dark orange shaded colour shows those areas with the highest number of unserved people per hexagon. The backlog is mainly in the former disadvantaged township areas.

Table 3. Service coverage statistics - Universal population

\begin{tabular}{lccccc}
\hline \multicolumn{1}{c}{ Settlement type } & $\begin{array}{c}\text { Served } \\
\text { \#people }\end{array}$ & $\begin{array}{c}\text { Served people } \\
(\mathbf{\%})\end{array}$ & $\begin{array}{c}\text { Unserved } \\
\text { people }\end{array}$ & $\begin{array}{c}\text { Unserved } \\
\text { people (\%) }\end{array}$ & $\begin{array}{c}\text { Total } \\
\text { population }\end{array}$ \\
\hline Suburban core & 1679921 & $55.3 \%$ & 1357691 & $44.7 \%$ & 3037611 \\
$\begin{array}{l}\text { Low density } \\
\text { outlying }\end{array}$ & 14862 & $17.0 \%$ & 73134 & $83.0 \%$ & 87996 \\
City of Tshwane & $\mathbf{1 6 9 4 8 7 2}$ & $\mathbf{5 4 . 2 \%}$ & $\mathbf{1 4 3 0 ~ 7 3 5}$ & $\mathbf{4 5 . 8 \%}$ & $\mathbf{3 ~ 1 2 5 ~ 6 0 7}$ \\
\hline served implies that people are allocated to a station with spare capacity and within the response time standard
\end{tabular}

Table 3 shows service coverage results based on the universal population demand and taking into consideration both distance and capacity constraints. Of the 3125607 people living in the City, only $55.3 \%$ are with reach of a station with vehicle capacity and within the required response time standard. An analysis for the 40 minute response time standard for low density outlying areas was not applied for this demand scenario since $99 \%$ of ambulance vehicle capacity had been fully allocated and most stations had run out of capacity. Based on the ratio of one ambulance per 30000 people as applied, the results show that there is a backlog of 48 ambulance vehicles that need to be additionally distributed across the poorly served areas. When the demand with respect to the second scenario was tested (that is based on the demand from only the uninsured population), there are major changes spatially in the areas that can be serviced. Figure 4: Map 2 shows areas that are serviced within the required standard when only uninsured people are considered. On the map it can be seen that there is 
a potential increase in the area served. The most noticeable change under this scenario is the increased ability to potentially service extensive areas in the outlying areas and along the main arterial routes though the area.

Figure 4: Map 4 shows areas that will remain unserved based on the same response time and capacity standards applied. When compared with the scenario 1 (universal population demand) results there is a decrease in the backlog in terms of the number of ambulance vehicles required based on the ratio of one ambulance per 30000 people, such that 31 rather than 48 new ambulance vehicles are required which has a significant impact in terms of resources with respect to vehicles, staff and operational budget.

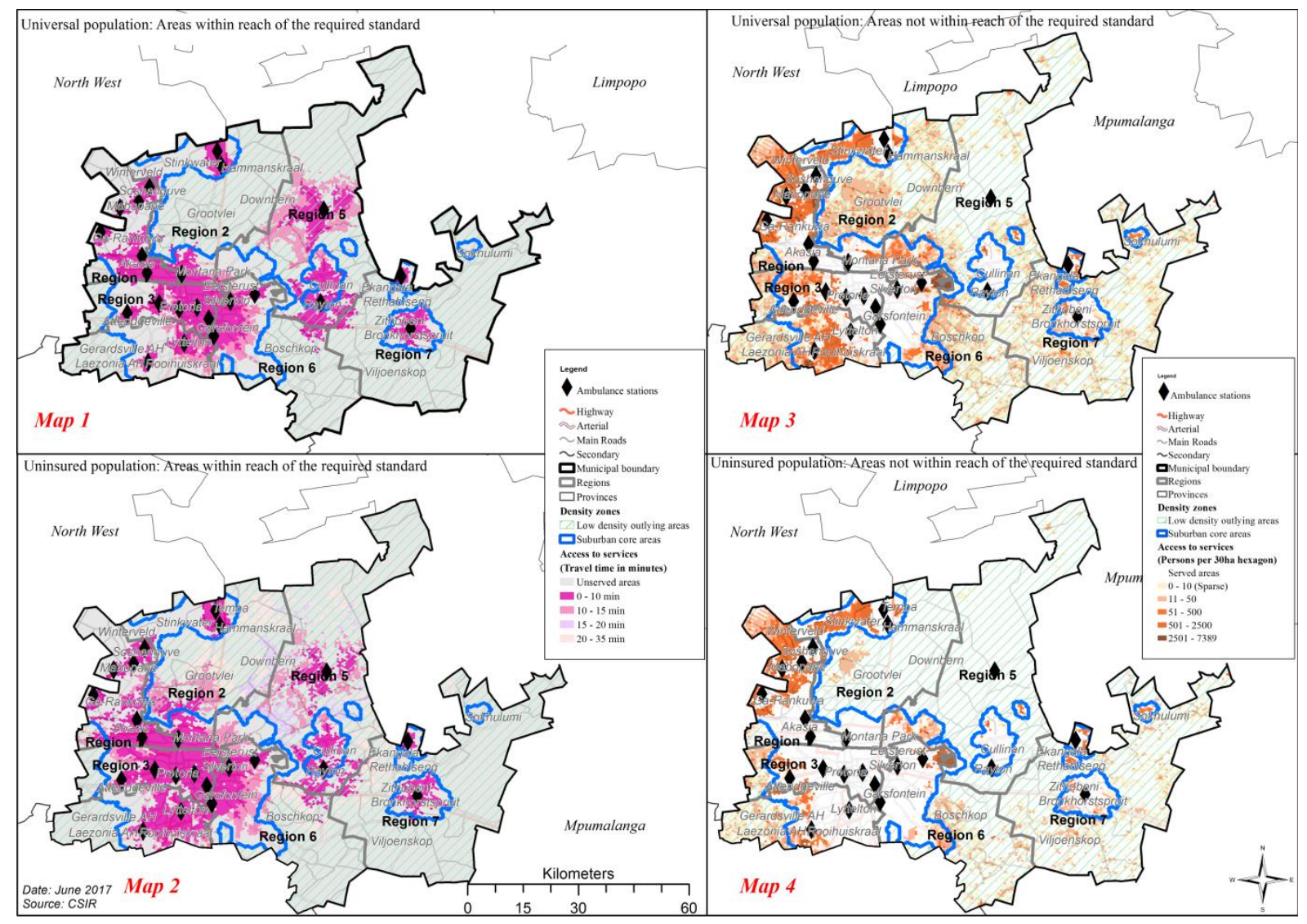

Figure 4: Density of population within reach / not within reach within the required response standards-Universal and Uninsured population demand

Table 4 shows service coverage statistics for the uninsured population demand scenario with an improvement of $6 \%$ to reach a $61 \%$ service coverage overall. The major impact is seen in the outlying rural area results. It will have an impact on spatial allocation of new vehicles but this cannot be discussed here. 
South African Journal of Geomatics, Vol. 6. No. 2, Geomatics Indaba 2017 Special Edition, August 2017

Table 4: Uninsured population - level of service coverage

\begin{tabular}{lcccccc}
\hline $\begin{array}{l}\text { Settlement } \\
\text { type }\end{array}$ & $\begin{array}{c}\text { Served } \\
\text { population }\end{array}$ & $\begin{array}{c}\text { Served } \\
\text { population } \\
\%\end{array}$ & $\begin{array}{c}\text { Unserved } \\
\text { population }\end{array}$ & $\begin{array}{c}\text { Unserved } \\
\text { population } \\
\%\end{array}$ & $\begin{array}{c}\text { Total } \\
\text { population }\end{array}$ & $\begin{array}{c}\text { Uninsured } \\
\text { population }\end{array}$ \\
\hline $\begin{array}{l}\text { Suburban } \\
\text { core }\end{array}$ & 1403241 & $60.9 \%$ & 900312 & $39.1 \%$ & 3533735 & 2303553 \\
$\begin{array}{l}\text { Low } \\
\text { density }\end{array}$ & 44994 & $63.8 \%$ & 25491 & $36.2 \%$ & 49944 & 70485 \\
$\begin{array}{l}\text { outlying } \\
\text { City of } \\
\text { Tshwane }\end{array}$ & $\mathbf{1 4 4 8 2 3 5}$ & $\mathbf{6 1 . 0 \%}$ & $\mathbf{9 2 5} \mathbf{8 0 3}$ & $\mathbf{3 9 . 0 \%}$ & $\mathbf{3 5 8 3 6 7 9}$ & $\mathbf{2 3 7 4 0 3 8}$ \\
\hline
\end{tabular}

In the sufficiency analysis, for the universal population demand scenario has potential service coverage of 54\% in contrast to the uninsured population scenario where $61 \%$ of the demand is served. This is mainly due to the reduction of demand in the high income areas of the city. In the low income areas where majority of the population do not have medical aid, the number of unserved people remains high.

\section{Recommendations and intervention}

The results show that the current ambulance stations are well distributed across the City, but that the main concern is the backlog with respect to the number of ambulance vehicles provided at stations to meet local demand when tested against the 1 vehicle: 30000 people provision standard. Based on this analysis it would be recommended that up to 48 ambulance vehicles are required to meet the backlog to serve the universal demand scenario and 31 ambulance vehicles to serve the uninsured population scenario. If the provincial provision standard of 1: 45000 people which is less restrictive were used, the vehicle demand would be reduced by approximately $30 \%$. No detail analysis for this was required as the spatial location is good and only vehicle numbers need to be addressed.

\section{Limitations and challenges}

Conclusions drawn from this study are based solely on the location of ambulance stations and ambulance response time targets. A number of other factors affect ambulance response times including: management and supervision, infrastructure, operations, emergency centres operation, actual service demand, administration and, communications (Robertson, 2009) as well as the response systems design (Stein et al., 2015). It was not possible to consider all these factors in the study; none the less, the results were able to provide valuable input with regards to capital investment planning and resource allocation based on two different target demand groups. The implication for both can now be used as input for management and planning.

The study created a demand distribution for the service based on population density, other factors such as traffic accidents and other high risk activities will add a different dimension to demand on the service. Other challenges include availability of readily usable data. Although the road network was available there was a need to customise average emergency road speeds achievable by ambulance vehicles. This process was extremely time consuming and required inputs from City of Tshwane 
Emergency Services Department staff based on their local knowledge. It was also not possible to obtain actual usage data on ambulance vehicles to compare this to the model results for the two scenarios.

\section{Conclusions}

GIS provides the platform to test different scenarios for service delivery. The scenarios are based on varying standards. Through the comparison of the outputs from the different scenarios, viable service provision standards could be determined and resultantly an appropriate planning process, which is spatially specific, put in place. The analysis enabled the evaluation of potential public ambulance service reach that provided empirical evidence that can be used in developing spatial planning frameworks for the City and contributes to its capital investment programmes. In other words, the analysis provides clear evidence of how much of what is needed where and based on that the City can determine the cost of providing ambulances at a certain standard of service delivery. Furthermore, this type of analysis enables an equitable distribution of facilities as it considers the entire City as an integrated system and does not only evaluate services per station. Ultimately an intervention strategy for both scenarios could be developed and tested with respect to the allocation of vehicles for purposes of investment consideration, budgeting and future long term planning.

\section{References}

Mokgalaka, H, Mans, G, Smit, J, \& McKelly, D 2014, 'Validating the accuracy of GIS-based accessibility analysis in determining public primary health care demand in metropolitan areas', in J. Whittal, S. Motala, (eds.), Second AfricaGEO Conference, 1-3 July 2014, Cape Town, South Africa, ISBN 978-0-620-60666-0.

Mans, G 2011, 'Developing a geo-data frame using dasymetric mapping principles to facilitate data integration', AfriGEO Conference: Developing Geomatics for Africa, Cape Town, May-June 2011.

Mokgalaka, H 2014, 'Measuring Access to Primary Health Care: Use of a GIS-Based Accessibility Analysis', in Y. Patel, N. Minyuku, C. Van Der Bank, K. Mohan and A. Ogra (eds.), Sixth Planning Africa Conference, 19-22 October 2014, pp. 217-239. Durban, South Africa. ISBN: 978-0-9921820-0-7.

Naudé, AH, Green, CA, \& Morojele, N 2001/2, 'Specific analysis measures and procedures in support of service access planning'. Access Planning Support Guide-2.CSIR: Transportek. Pretoria, pp. 33-45.

Green, C, Mans, G, Schmitz, P, McKelly D \& te Water, M 2014, 'Planning for emergency services using GIS-based geographic accessibility analysis'. Town and Regional Planning, a special edition on: Indicative datasets and tools that analyse spatial change: findings and implications for planning in South Africa. ISSN 1012-280, No 64, pp. 53-64.

Green, C, Breetzke, K, Mans G 2009, 'GIS-based evaluation of public facility provision to achieve improved governance and equitable service delivery', in Manfred Schrenk, Vasily V. Popovich, Dirk Engelke, Pietro Elisei (eds.) Real CORP Proceedings / Tagungsband, ISBN: 978-3-9502139-7-3, pp, 22-25, viewed 18 July 2017, http://www.corp.at

Geertman, SCM, de Jong, T, Wessels CGAM, \& Bleeker, J 2003, 'The relocation of ambulance facilities in central Rotterdam', in M. Clarke \& J. Stillwell (eds.), Applied GIS and Spatial Analysis, pp. 215-232, London: Wiley.

Guargliardo, MF 2004, 'spatial accessibility of primary care: concepts, methods and challenges'. International Journal of Health Geographics, Volume. 3, Num. 3, viewed 13 June 2017, https://ij-healthgeographics.biomedcentral.com/articles/10.1186/1476-072X-3-3 
Stein, C, Wallis, L, \& Adetunji, O 2015, 'Meeting national response time targets for priority 1 incidents in an urban emergency medical services system in South Africa: More ambulances won't help', South African Medical Journal, Vol. 105, No. 10, PP. 840-844.

Green, CA, Naude, A \& Ritsema van Eck, J 1998, 'Accessibility analysis techniques to locate new public transport interchanges and public facilities'. Codatu Conference, 1998.

Patel1, AB, Waters, NM, Blanchard, IE, Doig, CJ, \& Ghali1, WA 2012, 'A validation of ground ambulance pre-hospital times modelled using geographic information systems', International Journal of Health Geographics, https://ij-healthgeographics.biomedcentral.com/articles/10.1186/1476-072X-11-42

Kolesar, P, Blum, E, 1973 'Square root law for fire engine response distances'. Manage Science, Vol 19, No 12, PP. 1368-1378.

Dr C. Robertson. 2009. 'Factors that impact the ambulance response time performance in the Cape Town Metropolitan area', unpublished report.

Stein, C, Wallis, L, \& Adetunji, O 2015, 'The effect of the Emergency Medical Services vehicle location and response strategy on response times', South African Journal of industrial engineering, Vol. 26, No. 2, PP. 26-40. 